\title{
Discussion: scientific journalism
}

Charles Oppenheim

Pusztai intends to make his unrefereed data concerning his experiments with feeding genetically modified potatoes to rats available on the Web. Would you welcome this move?

\section{Bernard Dixon}

In fact, this data is already available on the Web, and has already been criticised - the Royal Society has suggested that it would not have been accepted by mainstream journals. This is an example of the changes that are currently occurring in publishing, as the data has not been published in the traditional way, and so it has avoided the peer review process. Responsible journalists should recognise that critical review is very important and should not simply accept and publish data without critically assessing it first.

Peter Burnhill

How was Pusztai's work published?

\section{Bernard Dixon}

Pusztai is a very distinguished scientist but his appearance on a World in Action programme, speaking in a very general way, meant that he was manipulated by a production team who had their own agenda and wanted to create the story.

\section{David Whitaker}

This question is asked of both speakers. Is there a dichotomy between a call for openness on the one hand, and the call to submit data to peer review? Are Government scientists 'good' scientists?"

\section{Ros Herman}

The majority of Government scientists have not been civil servants throughout their careers, they are academics who enter Government. They are increasingly not 'under the thumb' of the Government. It is unfortunate that the numbers of scientists who work in Government laboratories have declined, as this has led to a corresponding decrease in independently commissioned research. It is more and more the case that academics are becoming increasingly beholden to industrial paymasters.

\section{Arnold Wolfendale}

Peer review is vitally important - journalists need some kind of code of practice.

\section{Bernard Dixon}

This is difficult - in the genetically modified foods debate, people have now formed their own opinions. Scientists have not taken the opportunity to be proactive by explaining to the public what they are doing and why they are doing it. The media are not fed with enough good and interesting material with which to work. Scientists need to gain an understanding of how the media work, and then try to work with the media. 
Ros Herman

Journalists want to be read - that is their aim. So they need stories that they believe that people will want to read. Pharmaceutical companies are accomplished at public relations and feed positive stories to the media.

Arnold Wolfendale

If scientists were to have a hippocratic oath, what should it be?

Ros Herman

One - an ethic of openness. Two - a website/email address so that members of the public can have their say. Three - a recognition that they do not live in a vacuum.

Bernard Dixon

Scientists must realise how important public perceptions of their work really are. Even if they do, they can sometimes misjudge the public mood and what it wants to hear. For example, a scientist working on a virus to increase its virulence was using a scorpion gene and went public with this.

Don King

Is there any way that the scientific community could create a list of questions that journalists could ask about a piece of research; for example, "Was there a control?" This would allow the public to make their own judgements if it was included in the reporting.

\section{Bernard Dixon}

This is a good idea. The National Association of Science Writers in the USA has a booklet that deals with this area. People are beginning to recognise the importance of scientific method when assessing science stories.

\section{Peter Leggate}

We should be concerned with communicating the scientific process and probabilities rather than the scientific facts to the public.

\section{Ros Herman}

Journalists should provide information through stories. The change of government has improved the flow of information. There is no longer an aura of secrecy, fear, authority and hype. 